\title{
An Autopsy Case of Intimal Sarcoma of the Abdominal Aorta with Bone Metastasis and Lymph Node Metastasis: A Case Report and Review of the Japanese Literature
}

\author{
Masamichi Ueda ${ }^{1}$, Yuko Takeuchi ${ }^{1}$, Jun Ochiai ${ }^{1}$, Chiyuki Mabuchi ${ }^{1}$ and Nobuko Ujihira ${ }^{2,3}$
}

\begin{abstract}
A 73-year-old man complained of sternoclavicular joint pain; blood tests revealed elevated C-reactive protein. The patient developed delirium; magnetic resonance imaging showed metastatic bone tumors. He died two weeks after admission. Autopsy revealed abdominal aortic intimal sarcoma with metastasis to the peritracheal lymph nodes and sternum. Peripheral arterial embolism and bone metastasis are common symptoms of aortic intimal sarcoma, which implies a place for aortic intimal sarcoma in differential diagnoses of embolism or bone tumors of unknown origin.
\end{abstract}

Key words: abdominal aortic intimal sarcoma, lymph node metastasis, bone metastasis, delirium, elevated Creactive protein

(Intern Med 56: 791-796, 2017)

(DOI: 10.2169/internalmedicine.56.7576)

\section{Introduction}

Primary aortic intimal sarcoma is a rare disease. The first case of aortic intimal sarcoma in Japan was reported in 1989 by Miyakoshi; to date, there have been 14 reported cases in Japan (1-14). Most patients develop tumor embolisms, but because early diagnosis is difficult, the disease has a poor prognosis and is often first diagnosed in autopsy $(1,2,4,6,13-18)$.

We report a 73-year-old man who was diagnosed on autopsy with abdominal aortic intimal sarcoma. He presented with pain in the left sternoclavicular joint, an elevated serum C-reactive protein (CRP) level, and delirium as initial symptoms. We report this unique case, in which the patient developed pain consequent to bone metastasis and had lymph node metastasis.

\section{Case Report}

A 73-year-old man with delirium was admitted to our hospital complaining of left sternoclavicular joint pain. He had a history of diabetes mellitus, dyslipidemia, and stent placement for right renal arterial stenosis in 2011. In early August 2013, he experienced pain around the left sternoclavicular joint, and approximately the same time, he was unable to use either the television remote control or his car seatbelt. Although he visited his local physician several times, his symptoms did not improve and blood tests revealed no significant abnormalities except for an elevated CRP level. In mid-August, he developed delirium, and came to our hospital for detailed examination.

Physical examination findings on admission included: height, $160 \mathrm{~cm}$; weight, $63 \mathrm{~kg}$; body temperature, $36.8^{\circ} \mathrm{C}$; blood pressure, $150 / 89 \mathrm{mmHg}$; and heart rate, 100 beats/ min. Pressure pain was observed in his chest at the left and right sternoclavicular joints, sternum, and near the right fourth and fifth ribs. Examination of the head, abdomen, back, and limbs revealed no abnormalities, and no lymph node swelling was noted. Neurologically, the patient presented with slightly reduced consciousness; his Glasgow Coma Scale score was 14 (E4V4M6); however he scored 9 of a possible 30 on Hasegawa's Revised Dementia Scale. No neck stiffness was seen, and no cranial nerve, motor system,

${ }^{1}$ Department of Neurology, Nagoya Ekisaikai Hospital, Japan, ${ }^{2}$ Department of Pathology, Nagoya Ekisaikai Hospital, Japan and ${ }^{3}$ Present Address: Department of Pathology, Toyota Kosei Hospital, Japan

Received for publication April 25, 2016; Accepted for publication August 16, 2016

Correspondence to Dr. Masamichi Ueda, masamichi.ueda@gmail.com 


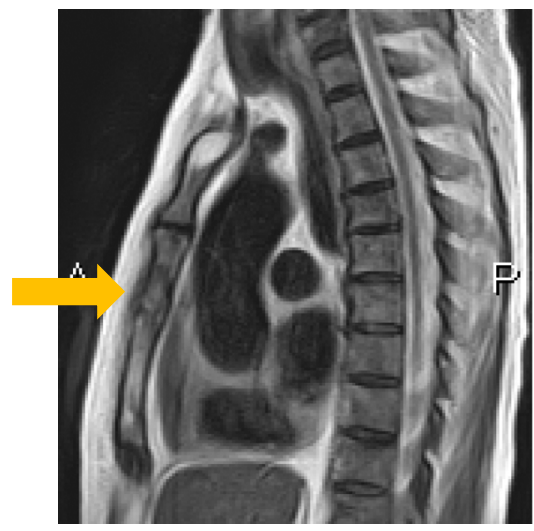

T2-weighted image

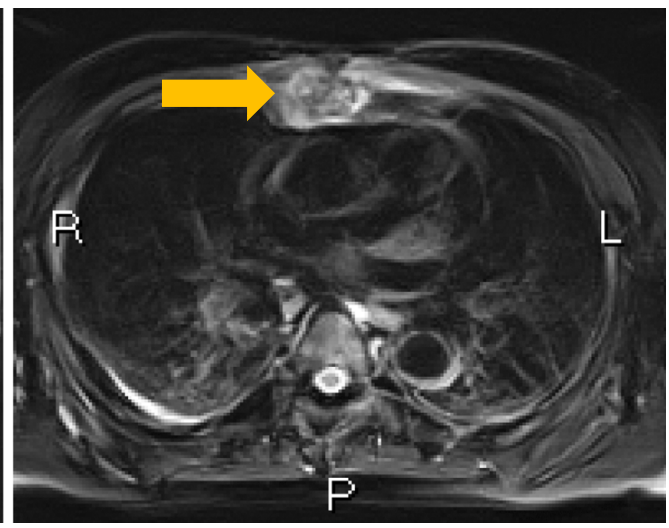

Fat-suppressed T2-weighted image

Figure 1. Mediastinal magnetic resonance imaging shows high signal intensity on T2-weighted imaging (arrow), and also on fat-suppressed T2-weighted imaging (arrow).

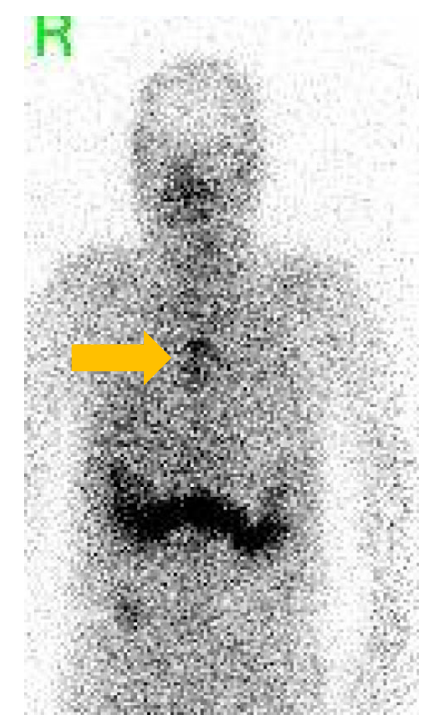

Figure 2. Gallium-67 scintigraphy images in the anterior view (48 hours): showing abnormal uptake in the sternum (arrow).

or sensory system abnormalities were observed. No symptoms of Parkinsonism, such as muscle rigidity and tremors, were noted.

Laboratory testing performed on admission revealed the following: white blood cell count, $7.4 \times 10^{3} / \mu \mathrm{L}$ (reference range: $4.5-7.7 \times 10^{3} / \mu \mathrm{L}$ ); CRP, $20.04 \mathrm{mg} / \mathrm{dL}$ (reference range: $0.0-0.3 \mathrm{mg} / \mathrm{dL}$ ); red blood cell count, $3.13 \times 10^{6} / \mu \mathrm{L}$ (reference range: $4.32-5.07 \times 10^{6} / \mu \mathrm{L}$ ); hemoglobin, $8.3 \mathrm{~g} / \mathrm{dL}$ (reference range: $13.5-15.7 \mathrm{~g} / \mathrm{dL}$ ); serum iron, $33 \mu \mathrm{g} / \mathrm{dL}$ (reference range: $100-150 \mu \mathrm{g} / \mathrm{dL}$ ); ferritin, $1,276.6 \mathrm{ng} / \mathrm{mL}$ (reference range: 18.6-261 ng/mL); blood glucose, $254 \mathrm{mg} / \mathrm{dL}$ (reference range: $70-109 \mathrm{mg} / \mathrm{dL}$ ); and hemoglobin A1c, $8.6 \%$ (reference range: 4.6-6.2\%). Electrolytes, vitamins, renal function, and hepatic function were normal. Blood coagulation testing revealed fibrin degradation products, $5.5 \mu \mathrm{g} / \mathrm{mL}$ (reference range: $0-10 \mu \mathrm{g} / \mathrm{mL}$ ), and D-dimer, $1.2 \mu \mathrm{g} / \mathrm{mL}$ (reference range: $0.0-1.0 \mu \mathrm{g} / \mathrm{mL}$ ). Serum immunological testing revealed no specific abnormalities. Levels of tumor markers revealed that soluble interleukin-2 receptor (sIL-2R) level was 1,350 IU/mL (reference range: 124-466 IU/mL), and no other abnormalities. As indicated, blood test results showed elevated levels of CRP, ferritin, sIL-2R, fibrin degradation products, and D-dimer. Examination of cerebrospinal fluid revealed a nucleated cell count of $0 / \mu \mathrm{L}$ (reference range: $0-5 / \mu \mathrm{L}$ ); protein, $83 \mathrm{mg} / \mathrm{dL}$ (reference range: $10-40$ $\mathrm{mg} / \mathrm{dL}$ ); glucose, $102 \mathrm{mg} / \mathrm{dL}$ (reference range: >one half of blood sugar); anti-N-methyl-D-aspartate antibody was negative. Results of polymerase chain reaction testing for herpes simplex virus deoxyribonucleic acid (DNA) and cytodiagnosis were negative. Magnetic resonance imaging (MRI) of the head revealed no particular abnormalities.

Following admission, the patient often developed severe delirium at night and complained of pain in the left and right sternoclavicular joints, sternum, and right fourth and fifth ribs. MRI of the mediastinum revealed a low-intensity signal in the sternum on T1-weighted imaging (T1WI) and a high-intensity signal on T2-weighted imaging (T2WI) and fat-suppressed T2WI (Fig. 1). A low-intensity signal was observed in the right pedicle of the upper thoracic spine on T1WI, and a tumor shadow with a high-intensity signal was seen on T2WI. Gallium scintigraphy revealed abnormal uptake in the sternum (Fig. 2). Further blood test results showed an elevated CRP level; however, there were no signs of infection, such as fever. Results of blood, urine, and cerebrospinal fluid cultures were also negative. The primary tumor could not be identified by MRI or scintigraphy findings. However, a metastatic or multifocal bone tumor was suspected. After two weeks of testing to identify a primary tumor lesion, the patient developed vomiting and abdominal pain and subsequently died.

An autopsy was performed approximately 2 hours after the patient's death. Macroscopic pathological findings revealed necrosis extending from the duodenum to the ileum. No macroscopic lesions were observed in the ribs or vertebrae, and no macroscopic masses were observed in the lungs, esophagus, stomach, intestinal tract, liver, spleen, pancreas, bladder, prostate, testicles, or kidneys. Calcification 
(A)

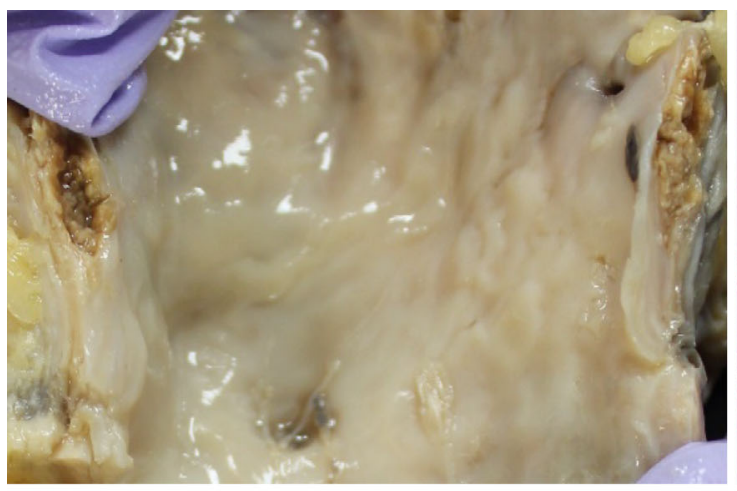

(C)

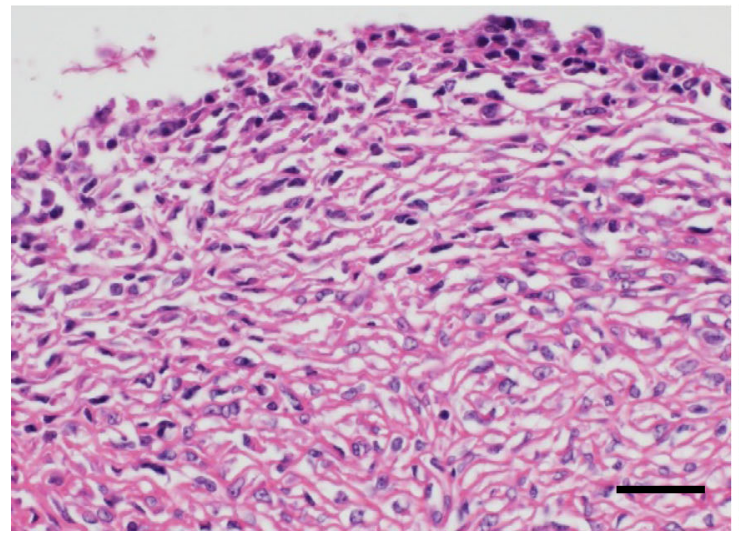

(B)

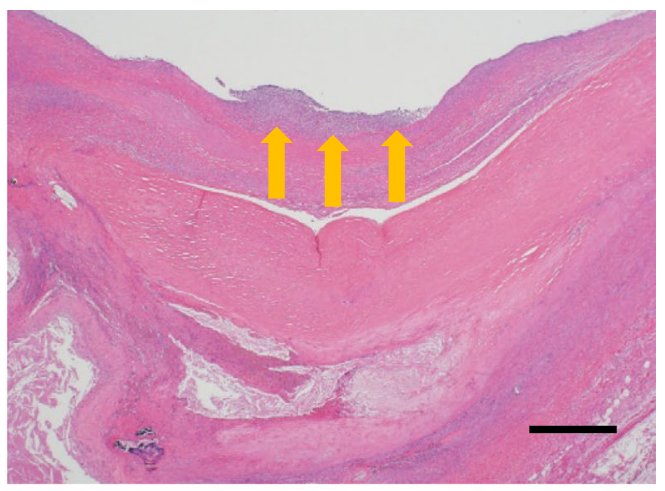

(D)

Figure 3. Pathological findings of the aorta. (A): Macroscopically, the aorta shows no tumorous lesion. (B): The aorta shows tumorous lesion in the intima [arrow; Hematoxylin and Eosin (H\&E) staining, bar: $1 \mathrm{~mm}$ ]. (C): Spindle tumor cells proliferate at the intimal surface (H\&E staining, bar: $40 \mu \mathrm{m})$. (D) Tumor cells stain positive for vimentin (vimentin stain, bar: $40 \mu \mathrm{m}$ ).

(A)

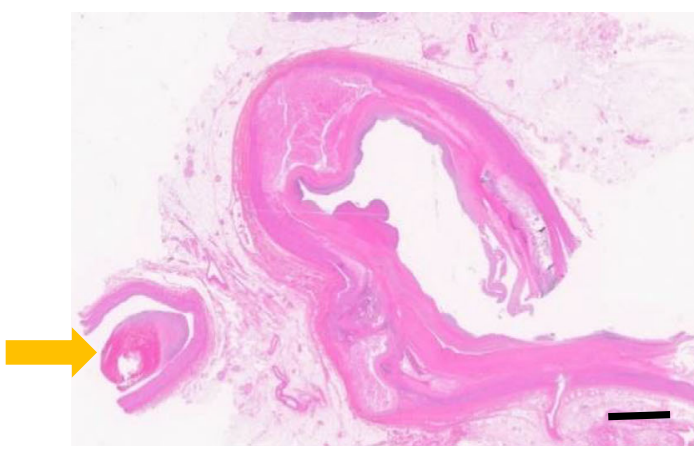

(B)

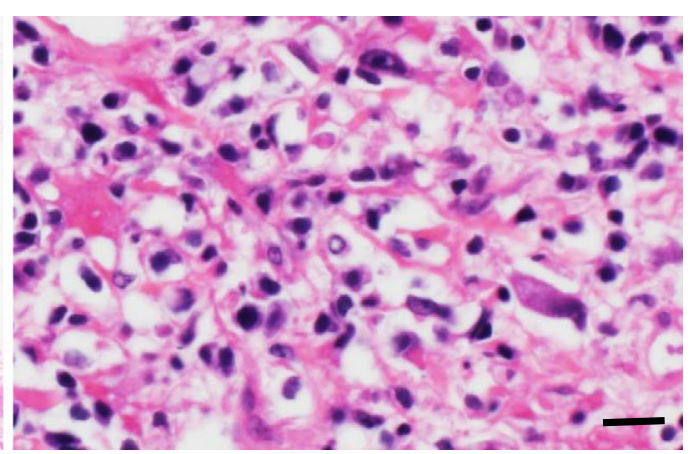

Figure 4. Pathological findings of the superior mesenteric artery. (A): The superior mesenteric artery is obstructed by a fibrin thrombus [arrow, Hematoxylin and Eosin (H\&E) staining, bar: 5 mm]. (B): The superior mesenteric artery is obstructed by a fibrin thrombus including tumor invasion (H\&E staining, bar: $20 \mu \mathrm{m}$ ).

was seen in the coronary arteries, but no valve vegetation was observed. No macroscopic masses were observed in the aorta from the chest to the abdomen. Spindle tumor cells were observed microscopically in the abdominal aortic intima. We could not find tumor cells in lymphatic vessels. Immunohistochemical staining of tumor cells were positive for vimentin (Fig. 3), which suggests that the tumor cells were derived from mesenchymal cells. Among other tested markers, AE1/AE3, S-100 protein, CD56, and desmin were negative; $\alpha$ SMA (smooth muscle actin) and HHF-35 (muscle-specific actin) were almost negative; and Ki-67 was positive for $16 \%$ cells. Spindle tumor cells were observed in the superior mesenteric artery (Fig. 4). Proliferation of spindle tumor cells was observed in the ribs, thoracic vertebrae, 
(A)

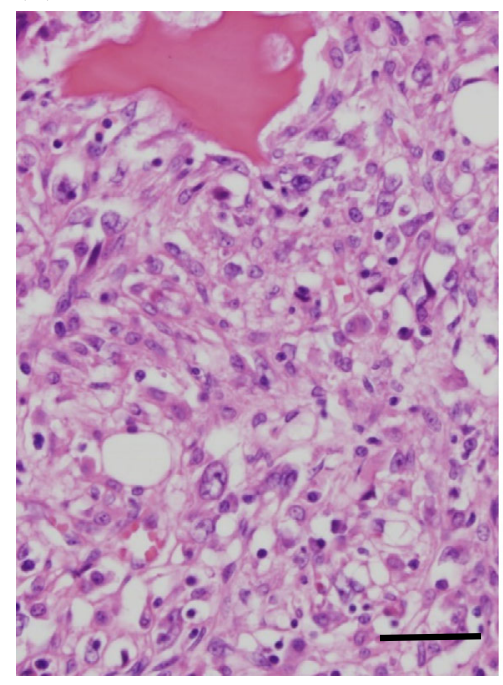

(B)

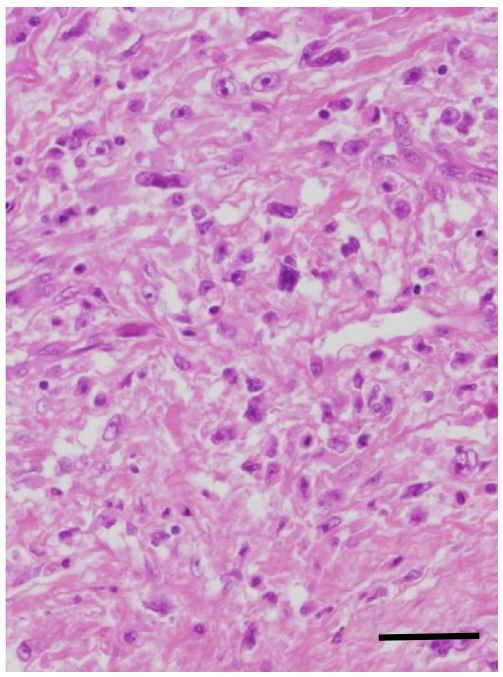

Figure 5. Pathological findings of the metastatic lesion. (A) Micrograph confirming metastasis in the sternum [Hematoxylin and Eosin (H\&E) staining, bar: $50 \mu \mathrm{m}]$. (B) Micrograph confirming metastasis in the peritracheal lymph node (H\&E staining, bar: $50 \mu \mathrm{m})$.

sternal medullary cavity near the sternoclavicular joint, and peritracheal lymph nodes (Fig. 5). No tumor cells were seen from the ascending aorta to the thoracic aorta, pulmonary artery, or renal artery stent. In the neuropathological examination, no tumor cells were seen in the brain. Several Lewy bodies were observed throughout the entire cerebral cortex and brain stem. However, there was not severe neuronal loss in the cerebral cortex and was not apparent gliosis. No perivascular lymphocytic infiltration and no cerebellar degeneration were seen. Based on these findings, we diagnosed abdominal aortic intimal sarcoma with multifocal bone metastasis and peritracheal lymph node metastasis.

\section{Discussion}

Aortic intimal sarcoma is a malignant mesenchymal tumor that arises in the aorta, in which the defining feature is intraluminal growth that obstructs the lumen of the vessel of origin and seeding of emboli to peripheral organs $(17,18)$. Most patients with aortic intimal sarcoma are middle-aged and have symptoms of embolism $(17,18)$. Tumor emboli can cause intestinal ischemia and metastasis in bone, adrenal gland, spleen, brain, heart, kidney, liver, lung, and skin (18). The prognosis for patients with aortic intimal sarcoma is poor, with survival of only a few months $(17,18)$.

In our case, the pathological findings led to a diagnosis of abdominal aortic intimal sarcoma, revealing peritracheal lymph node metastasis and bone metastasis to ribs, vertebrae, and sternum near the sternoclavicular joint. Autopsy and immunohistochemical findings showed that tumor cells were mainly in the vessel and originated from mesenchyme.

Tumor embolism of the superior mesentery artery resulted in intestinal necrosis extending from the duodenum to the ileum, which was considered to be the direct cause of death. In the neuropathological examination, the patient exhibited no invasive tumor cells into the central nervous system. Recent study showed that acute-onset dementia might be relevant to paraneoplastic neurological syndrome, especially paraneoplastic encephalomyelitis (19). Most paraneoplastic neurological syndrome cases were accompanied by carcinoma such as small cell lung cancer, breast cancer, and gynecologic tumor (20). Only a few cases with paraneoplastic neurological syndrome accompanied by sarcoma have been reported. We could not clearly diagnose his psychiatric symptoms as Lewy body disease, bad general condition, or paraneoplastic neurological syndrome. Although his delirium might have been caused by Lewy body disease, it was intensified by the general deterioration.

A literature search revealed only 14 cases of primary aortic intimal sarcoma in Japan (1-14) (Table). Although the age at onset of this disease ranges from the 20 s to the $70 \mathrm{~s}$, it seems to be more common among older people, with seven of the 15 reported patients (including ours) being in their 70s. Initial symptoms commonly include symptoms related to embolism, such as pain in the abdomen, back, and extremities. The CRP levels were elevated in five of the 7 patients in whom CRP values were available, which suggests that many patients such as our case have elevated CRP. Of the three patients with psychiatric symptoms, delirium was noted only in our case, indicating that delirium is a rare symptom of this disease. Metastasis to multiple organs was reported in seven patients. Bone metastasis was the most common sign, followed by adrenal metastasis, renal metastasis, and splenic metastasis. Burke and Virmani reported a review of cases of aortic intimal sarcoma with metastasis to lymph nodes (21), but lymph node metastasis in this disease is rare. Although tumor cells may metastasize by blood flow, the mechanism and frequency of the metastasis to the lymph nodes are unclear and warrant further study.

Most cases of this disease present with symptoms of em- 
Table. Comparison of Our Patient's Characteristics with 14 Previous Japanese Case Reports of Primary Aortic Intimal Sarcoma.

\begin{tabular}{|c|c|c|c|c|c|c|c|}
\hline Case & Year & $\begin{array}{l}\text { Age/ } \\
\text { gender }\end{array}$ & Primary symptom & PL & CRP & Metastatic lesion & Cause of death \\
\hline 1 & 1989 & $50 / \mathrm{M}$ & back pain & TA & elevated & $\mathrm{Lu}, \mathrm{S}, \mathrm{K}, \mathrm{Bo}$ & MOF \\
\hline 2 & 1992 & $76 / \mathrm{M}$ & back pain & $\mathrm{T}$ & normal & $\mathrm{Ag}$ & MI \\
\hline 3 & 31996 & $54 / \mathrm{F}$ & fever & $\mathrm{T}$ & elevated & no & MOF \\
\hline 4 & $4 \quad 2000$ & $73 / \mathrm{M}$ & dyspnea & A & n.d. & $\mathrm{P}, \mathrm{S}, \mathrm{K}, \mathrm{Ag}$ & MOF \\
\hline 5 & 2002 & $75 / \mathrm{M}$ & abdominal pain & $\mathrm{T}$ & n.d. & $\mathrm{Li}, \mathrm{K}, \mathrm{Ag}, \mathrm{SI}$ & MOF \\
\hline 6 & $5 \quad 2002$ & $78 / \mathrm{M}$ & dyspnea & $\mathrm{T}$ & - & no & MOF \\
\hline 7 & 72005 & $63 / \mathrm{M}$ & lower limbs pain & TA & n.d. & no & MOF \\
\hline 8 & 2008 & $78 / \mathrm{M}$ & left upper limb pain & $\mathrm{T}$ & n.d. & no & survive \\
\hline 9 & 2008 & 49/M & trachyphonia & $\mathrm{T}$ & n.d. & no & survive \\
\hline 10 & 2009 & $69 / \mathrm{M}$ & back pain & $\mathrm{T}$ & elevated & no & survive \\
\hline 11 & 2010 & $69 / \mathrm{M}$ & back pain & $\mathrm{T}$ & n.d. & no & RT \\
\hline 12 & 2011 & $20 \mathrm{~s} / \mathrm{M}$ & abdominal pain & $\mathrm{T}$ & n.d. & no & survive \\
\hline 13 & 2013 & $70 / \mathrm{M}$ & fever & $\mathrm{T}$ & elevated & $\mathrm{Br}, \mathrm{Li}, \mathrm{S}, \mathrm{Bo}$ & pneumonia \\
\hline 14 & 2014 & $60 \mathrm{~s} / \mathrm{M}$ & dyspnea & $\mathrm{TA}$ & n.d. & Bo, $\mathrm{Ag}$ & heart failure \\
\hline our case & 2016 & $73 / \mathrm{M}$ & ostealgia & A & elevated & Bo, Ly & necrosis of SI \\
\hline
\end{tabular}

A: abdominal aorta, Ag: adrenal glands, Bo: bone, Br: brain, F: female, K: kidney, Li: liver, Lu: lung, Ly: lymph node, M: male, MI: myocardial infarction, MOF: multi-organ failure, n.d.: not documented, P: pancreas, PL: primary lesion, RT: recurrence of tumor, S: spleen, SI: small intestine, T: thoracic aorta, TA: thoracoabdominal aorta

bolism, and in some cases, the diagnosis was made by surgery $(3,5,7,9-12)$. However, antemortem diagnosis is difficult, and most cases are diagnosed by autopsy $(1,2,4,13$ 16). In all cases, prognosis is poor, with death generally occurring within several months of onset (15-18). Our patient presented with pain resulting from a metastatic tumor and elevated CRP prior to exhibiting symptoms of embolism. Of the patients listed in Table, only the patient reported by Yoshikawa et al. (13) and our patient are thought to have developed symptoms of this disease because of metastatic tumors. Although this disease is difficult to diagnose early, it must be considered in differential diagnoses of patients with elevated CRP levels who also show symptoms of embolisms of unknown origin or symptoms of metastatic tumors.

The authors state that they have no Conflict of Interest (COI).

\section{References}

1. Miyakoshi S, Nishikawa H, Nishimura S, Seki A, Honda K, Hara M. An autopsy case of the aortic intimal sarcoma. Shinzou (Heart) 21: 208-216, 1989 (in Japanese).

2. Otsubo M. A case of aortic intimal sarcoma with adrenal metastasis. Naika 70: 768-770, 1992.

3. Nanjo H, Murakami M, Ebina T, et al. Aortic intimal sarcoma with acute myocardial infarction. Pathol Int 46: 673-681, 1996.

4. Nishida N, Yutani C, Ishibashi-Ueda H, Tsukamoto Y, Ikeda Y, Nakamura Y. Histopathological characterization of aortic intimal sarcoma with multiple tumor emboli. Pathol Int 50: 923-927, 2000.

5. Omori H, Nio Y, Ogo Y, Itakura M, Torii I, Higami T. Superior mesenteric artery embolization by an aortic intimal sarcoma -a case report-. Nihon Rinshou Geka Gakkai Zasshi 63: 1387-1392, 2002 (in Japanese, Abstract in English).

6. Sato S, Tamada Y, Kaitsuma S, et al. An autopsy case of aortic intimal sarcomas with severe hypertension and congestive heart fail- ure. Nihon Naika Gakkai Zasshi 91: 1323-1325, 2002 (in Japanese).

7. Akiyama K, Nakata K, Negishi N, Henmi A. Intimal sarcoma of the thoracic aorta; clinical-course and autopsy finding. Ann Thorac Cardiovasc Surg 11: 135-138, 2005.

8. Kato W, Usui A, Oshima H, Suzuki C, Kato K, Ueda Y. Primary aortic intimal sarcoma. Gen Thorac Cardiovasc Surg 56: 236-238, 2008.

9. Ishigami N, Suzuki K, Takahashi T, Neyatani H, Bashar AHM, Kazui T. Intimal sarcoma of aortic arch treated with proton therapy following surgery. Asian Cardiovasc Thorac Ann 16: e12-e14, 2008.

10. Sudo M, Seki A, Tobaru T, et al. Intimal sarcoma of the aorta diagnosed from a thoracic aorta aneurysm. ICU \& CCU 33: 932935, 2009 (in Japanese, Abstract in English).

11. Tanaka M, Tabata M, Shimokawa T, Takanashi S. The rupture of descending thoracic aorta due to the necrosis of aortic intimal sarcoma. Interact Cardiovasc Thorac Surg 10: 462-464, 2010.

12. Yamada $T$, Yamamoto $H$, Aishima $S$, et al. A case of primary intimal sarcoma. Shindan Byouri 28: 145-148, 2011 (in Japanese, Abstract in English).

13. Yoshikawa H, Ishii $H$, Nakama $K$, Yokoyama A, Kushima H, Kadota J. An autopsy case of primary intimal sarcoma of the aortic arch. Nihon Kokyuuki Gakkaishi 2: 641-645, 2013 (in Japanese, Abstract in English).

14. Yamaguchi M, Kaizaki Y, Urasaki K, Fujino S. A case of primary aortic intimal sarcoma. Shindan Byouri 31: 310-314, 2014 (in Japanese, Abstract in English).

15. Ockert S, Böckler D, Winkler M, Palma P, Koeppel T, Post S. Intimal sarcoma of the infrarenal aorta: report of a rare single case and review of the literature. European Journal of Vascular and Endovascular Surgery 7: 76-80, 2004.

16. Isselbacher EM. Disease of the Aorta. In: Braunwald's Heart Disease. 7th ed. Zipes DP, Libby P, Bonow RO, et al., Eds. Elsevier, Philadelphia, 2005: 1403-1433.

17. Lesniewska BB, Rychter MD. Intimal sarcoma. In: WHO Classification of Tumours of Soft Tissue and Bone. 4th ed. Fletcher CDM, Bridge JA, Hogendoorn PCW, Mertens F, Eds. International Agency for Research on Cancer, Lyon, 2013: 232-234.

18. Burke A, Tavora FR, Maleszewski JJ, Frazier AA. Tumors of the 
heart and great vessels. In: AFIP Atlas of Tumor Pathology. 4th series. Caton MQ, Ed. Silver Spring, Maryland, 2015: 391-411.

19. Tanaka K. Paraneoplastic neurological syndrome with dementia Brain Nerve 68: 391-398, 2016 (in Japanese).

20. Hayashi Y, Inuzuka T. Paraneoplastic neurological syndrome and autoantibodies. Brain Nerve 65: 385-393, 2013 (in Japanese).

21. Burke AP, Virmani R. Sarcomas of the great vessels. Cancer 71:
1761-1773, 1993.

The Internal Medicine is an Open Access article distributed under the Creative Commons Attribution-NonCommercial-NoDerivatives 4.0 International License. To view the details of this license, please visit (https://creativecommons.org/licenses/ by-nc-nd/4.0/).

(C) 2017 The Japanese Society of Internal Medicine http://www.naika.or.jp/imonline/index.html 